\title{
Coexistence of Graves' disease and unilateral functioning Struma ovarii: a case report
}

\author{
Tullaya Sitasuwan ${ }^{1}$, Suchanan Hanamornroongruang ${ }^{2}$, Thavatchai Peerapatdit ${ }^{1}$ and Nuntakorn Thongtang ${ }^{1 *}$
}

\begin{abstract}
Background: Coexisting of Graves' disease and functioning struma ovarii is a rare condition. Although the histology of struma ovarii predominantly composed of thyrocytes, the majority of the patients did not have thyrotoxicosis. The mechanism underlying the functioning status of the tumor is still unclear but the presence of thyroid stimulating hormone receptor (TSHR) is thought to play a role. Here we describe the patient presentation and report the TSHR expression of the tumor.
\end{abstract}

Case presentation: A 56-year old Asian woman presented with long standing thyrotoxicosis for 23 years. She was diagnosed with Graves' disease and thyroid nodules. She had bilateral exophthalmos and had high titer of plasma TSHR antibody. Total thyroidectomy was performed and the histologic findings confirmed the clinical diagnosis. The patient had persistent thyrotoxicosis postoperatively. Thyroid uptake demonstrated the adequacy of the thyroid surgery and the whole body scan confirmed the presence of functioning thyroid tissue at pelvic area. The surgery was scheduled and the patient had hypothyroidism after the surgery. The pathological diagnosis was struma ovarii at right ovary. We performed TSHR staining in both the patient's struma ovarii and in 3 cases of non-functioning struma ovarii. The staining results were all positive and the intensity of the TSHR staining of functioning struma ovarii was the same as that in other cases of non-functioning tumors, suggesting that the determinant of functioning struma ovarii might be the presence of TSHR stimuli rather than the intensity of the TSHR in the ovarian tissue.

Conclusion: In patients with Graves' disease with persistent or recurrent thyrotoxicosis after adequate ablative treatment, the possibility of ectopic thyroid hormone production should be considered. TSHR expression is found in patients with functioning and non-functioning struma ovarii and cannot solely be used to determine the functioning status of the tumor.

Keywords: Graves' disease, Functioning struma ovarii

\section{Background}

Coexisting of Graves' disease and functioning struma ovarii is a rare condition. Struma ovarii is a rare ovarian tumor. Most affected patients are asymptomatic; however thyrotoxicosis from struma ovarii has been reported in $5 \%$ to $15 \%$ of the confirmed cases $[1,2]$. Although the histology of struma ovarii predominantly composed of thyrocytes, the majority of the patients do not have thyrotoxicosis. The mechanism underlying the functioning status of the tumor is still unclear. The expression of

\footnotetext{
* Correspondence: nuntakorn@hotmail.com

'Division of Endocrinology and Metabolism, Faculty of Medicine Siriraj

Hospital, Mahidol University, Bangkok 10700, Thailand

Full list of author information is available at the end of the article
}

thyroid-stimulating hormone receptor (TSHR) is thought to play a role $[3,4]$. The diagnosis of functioning struma ovarii is challenging especially when the patient had functioning thyroid gland. Here we report an usual case of coexisting Graves' disease with functioning struma ovarii and the TSHR staining result, including the TSHR staining of the patient with non-functioning struma ovarii.

\section{Case presentation}

A 56-year-old woman presented with persistent thyrotoxicosis. She was first diagnosed with thyrotoxicosis 23 years previously and had been periodically treated with antithyroid drugs for several years at a time. On examination, she had bilateral exophthalmos. Her thyroid gland was enlarged 
with palpable thyroid nodules. Her serum TSHR antibody level was elevated at $3.86 \mathrm{IU} / \mathrm{L}$ (reference range, $<1.00 \mathrm{IU} / \mathrm{L}$ ), thus confirming the diagnosis of Graves' disease with thyroid nodules.

A thyroid scan with $\mathrm{Tc}^{99} \mathrm{~m}$ showed generalized increased uptake in the thyroid gland with visualized activity in the pyramidal lobe. One hyperfunctioning nodule at the upper pole of the right lobe and another hypofunctioning nodule in the middle aspect of the right lobe were demonstrated (Fig. 1). The provisional diagnosis at that time was Graves' disease with thyroid nodules, and ablative treatment was planned. Ultrasound-guided fineneedle aspiration yielded an area of undetermined significance. Total thyroidectomy was performed without perioperative complications. The surgical specimen contained $57.7 \mathrm{~g}$ of thyroid tissue. The histological findings supported the clinical diagnosis of Graves' disease and benign thyroid nodules.

Two weeks after total thyroidectomy, the patient's symptoms of thyrotoxicosis recurred. The differential diagnosis included inadequate thyroidectomy or a source of extrathyroidal thyrotoxicosis such as functioning struma ovarii. A thyroid function test confirmed the presence of post-thyroidectomy thyrotoxicosis (Table 1). The radioactive iodine uptake was evaluated to check the adequacy of the thyroid surgery, and very low uptake of $0.2 \%$ was found in the thyroid bed (reference range, $15 \%-45 \%)$. A radioactive iodine $\left(\mathrm{I}^{131}\right)$ whole-body scan demonstrated intense radiotracer uptake with a star artifact in the pelvic region. Single-photon emission computed tomography/computed tomography of the

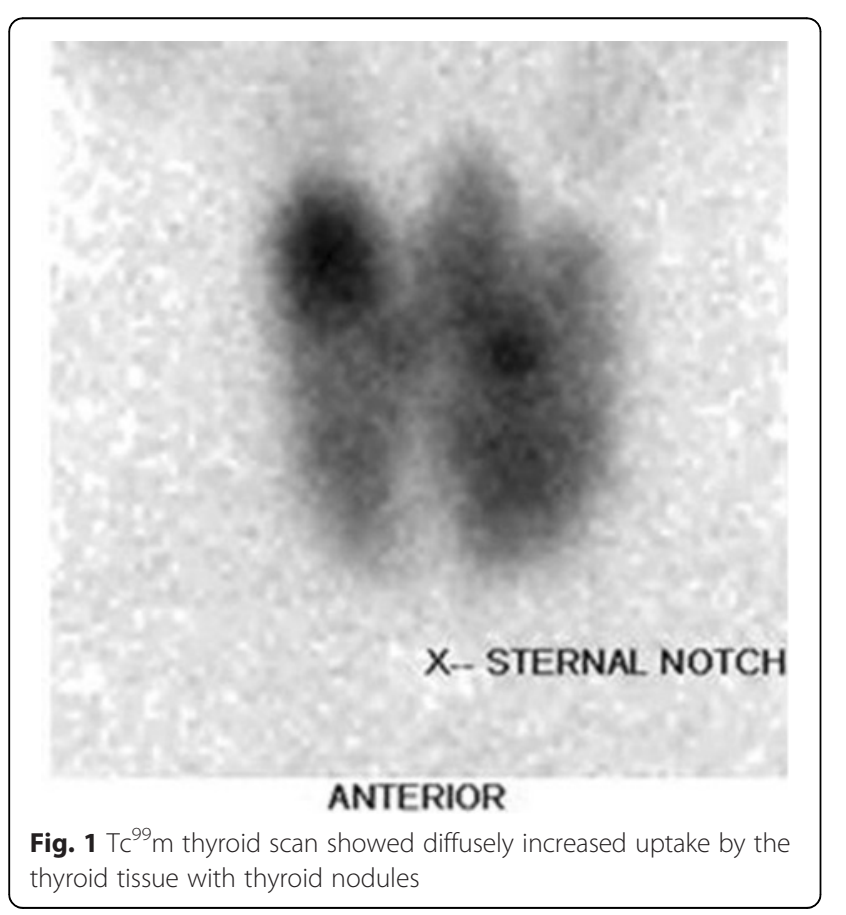

pelvis confirmed the presence of inhomogeneous increased radiotracer uptake by an $8.5-\times 7.2-\mathrm{cm}$ mixed multicystic-solid mass with internal calcification in the right adnexal region (Fig. 2). The plasma level of cancer antigen 125 was elevated at $48.55 \mathrm{U} / \mathrm{ml}$ (reference range, 0-35 U/ml). Therefore the patient was diagnosed with coexisting Graves' disease and functioning struma ovarii and surgery is scheduled. Preoperative control of thyrotoxicosis is required to prevent thyroid storm during the surgery. In the present case, therefore, the patient's methimazole was restarted, and a euthyroid state was achieved before scheduling total abdominal hysterectomy with bilateral salpingo-oophorectomy (TAH with BSO).

The patient's perioperative course was uneventful. An $8.0-\times 5.5-\times 5.0-\mathrm{cm}$ right ovarian mass with minimal ascites was found, the cut surfaces of the ovary showed solid-cystic appearance. The solid component showed soft red-brown and yellowish semitranslucent tissue resembling thyroid tissue. The cystic spaces contained clear yellow fluid.

The histological diagnosis was struma ovarii of the right ovary, without evidence of malignancy. Immunohistochemical staining for thyroglobulin (clone $2 \mathrm{H} 11+6 \mathrm{E} 1$; Cell Marque) was positive; this result confirmed the thyroid epithelial nature of the lesion (Fig. 3b). Moreover, immunohistochemical staining for TSHR (clone 4C1/E1/G8; Abcam) was performed with normal thyroid tissue as a positive control and normal ovarian tissue as a negative control. Immunohistochemical staining was performed by autostainer (Ventana Benchmark XT). The result showed that the struma ovarii tissue in our patient was positive for TSHR, indicating the presence of TSHR expression in the struma ovarii tissue (Fig. 3c). Two weeks postoperatively, the patient's thyroid hormone levels were in the hypothyroid range. Replacement therapy with levothyroxine was initiated, and euthyroidism was achieved.

\section{Discussion}

Struma ovarii is a rare ovarian germ cell tumor which is entirely or predominantly composed of thyroid tissue [5]. Struma ovarii has been reported in $0.3 \%$ to $1.0 \%$ of all ovarian tumors and $2.0 \%$ to $4.0 \%$ of all ovarian teratomas [1]. It commonly occurs in the fourth to sixth decades of life, and it is usually benign and unilateral. Most affected patients are asymptomatic. However, patients may seek medical attention because of compressive symptoms involving a nearby organ, ascites, or even thyrotoxicosis. Thyrotoxicosis from struma ovarii has been reported in $5 \%$ to $15 \%$ of the confirmed cases $[1-3,6]$, but it is noted to be rare for tumors of $<3 \mathrm{~cm}$ [7]. However, the actual incidence remains unclear owing to a lack of precise data on thyroid function in affected patients. Thyrotoxicosis in patients with struma ovarii has three potential causes: a hyperfunctioning struma ovarii alone, both a 
Table 1 Thyroid hormone levels and management at baseline and during follow-up

\begin{tabular}{|c|c|c|c|c|c|}
\hline & At first presentation & $\begin{array}{l}\text { Before total } \\
\text { thyroidectomy }\end{array}$ & $\begin{array}{l}2 \text { weeks after total } \\
\text { thyroidectomy }\end{array}$ & $\begin{array}{l}\text { Before TAH } \\
\text { with BSO }\end{array}$ & $\begin{array}{l}2 \text { weeks after } \mathrm{TAH} \\
\text { with } \mathrm{BSO}\end{array}$ \\
\hline Free $T_{4}(0.93-1.70 \mathrm{ng} / \mathrm{dl})$ & - & 1.14 & 4.8 & 1.43 & 0.11 \\
\hline Total $T_{4}(4.50-11.70 \mu \mathrm{g} / \mathrm{dl})$ & 17.27 & - & - & - & - \\
\hline Total T $3(80-200 \mathrm{ng} / \mathrm{dl})$ & 233 & 167.5 & 380.7 & 153.2 & - \\
\hline TSH (0.27-4.20 mlU/ml) & $<0.005$ & 0.01 & $<0.005$ & 0.16 & $>100$ \\
\hline Treatment & $\begin{array}{l}\text { Start propylthiouracil } \\
300 \mathrm{mg} / \text { day }\end{array}$ & $\begin{array}{l}\text { Methimazole } \\
7.5 \mathrm{mg} / \text { day }\end{array}$ & $\begin{array}{l}\text { Stop methimazole } \\
\text { for } 2 \text { weeks }\end{array}$ & $\begin{array}{l}\text { Methimazole } \\
2.5 \mathrm{mg} / \text { day }\end{array}$ & $\begin{array}{l}\text { Start levothyroxine } \\
100 \text { mcg/day }\end{array}$ \\
\hline
\end{tabular}

hyperfunctioning thyroid gland and a struma ovarii, or a hyperfunctioning thyroid gland with an incidental nonfunctioning struma ovarii [7]. The diagnosis of a functioning struma ovarii is challenging, especially in a patient with a hyperfunctioning thyroid gland. The evidence for the presence of a hyperfunctioning struma ovarii is based on increased radioiodine uptake by the ovary on an $\mathrm{I}^{131}$ whole-body scan [6]. Cervical goiter is quite common in patients with struma ovarii $(16 \%-40 \%)[1,2]$. Because Graves' disease is the most common cause of hyperthyroidism with diffuse thyroid gland enlargement, a number of previous cases of thyrotoxicosis due to struma ovarii were incorrectly treated by thyroidectomy $[6,7]$. The coexistence of Graves' disease and a hyperfunctioning struma ovarii is extremely rare. The characteristic of the prior case reports were summarized in Table 2 . In most cases, the diagnosis was based on persistent postoperative thyrotoxicosis. In only two cases were both coexisting diseases simultaneously diagnosed $[1,8]$. The optimal preoperative method for diagnosis of hyperfunctioning struma ovarii is either confirmation of the presence of thyrotoxicosis despite the absence of hyperfunctioning thyroid tissue or low radioiodine uptake at the neck along with high ovarian uptake of radioiodine tracer. Increased uptake of radioiodine by an ovarian tumor on a whole-body scan alone is insufficient for diagnosis of hyperfunctioning struma ovarii because it reportedly yields both false-positive and false-negative results [9-14]. The main differential diagnosis for increased uptake of radiotracer in the abdomen is ovarian metastasis from primary thyroid cancer.

Similar to most cases, the hyperthyroidism in our patient was thought to have arisen only from Graves' disease based on typical signs of diffuse thyroid gland enlargement, bilateral exophthalmos, diffuse thyroid uptake with visualized activity in the pyramidal lobe, and an elevated level of plasma TSHR antibody. However, persistent postthyroidectomy thyrotoxicosis with low $\mathrm{I}^{131}$ uptake at the

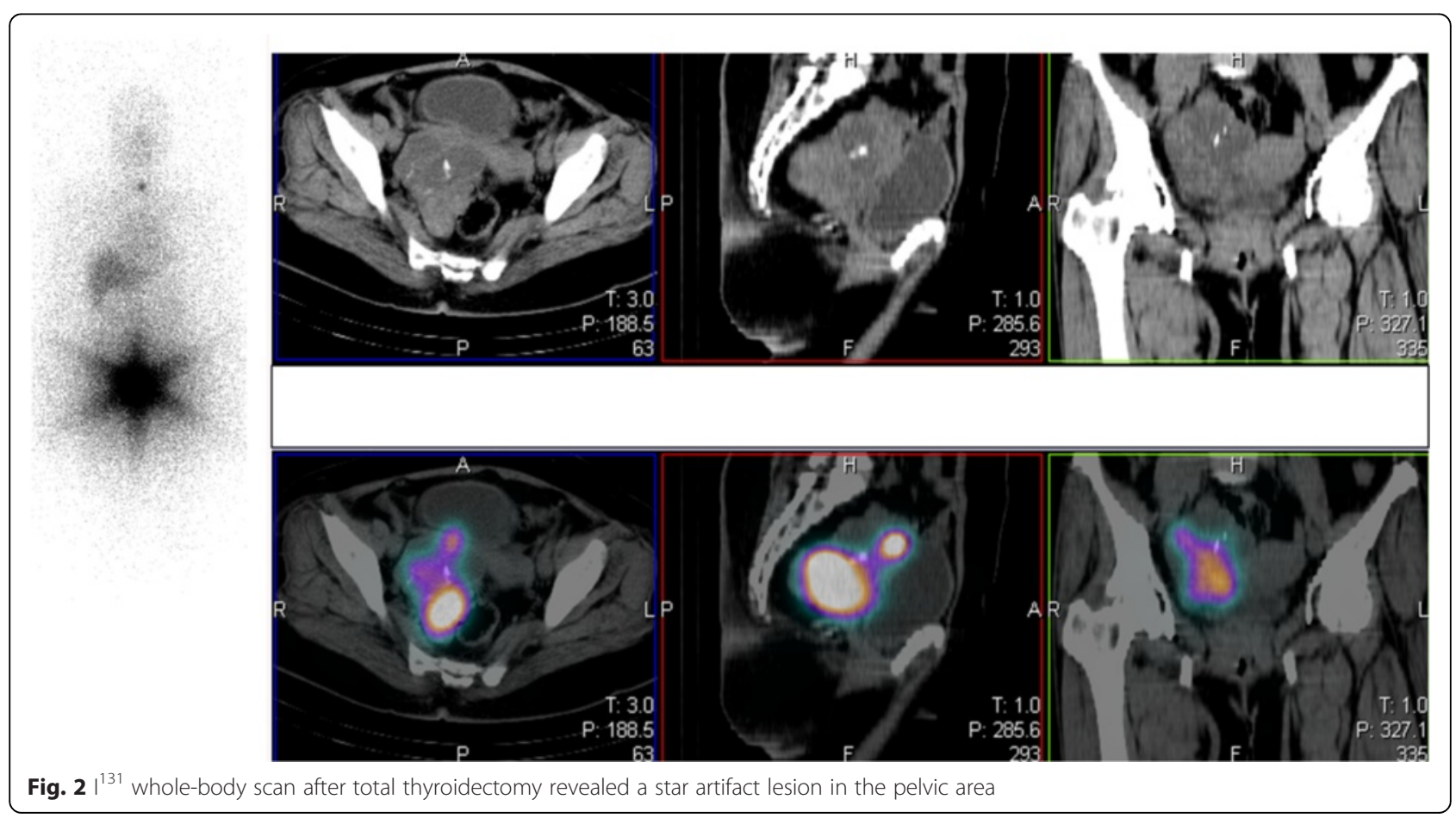



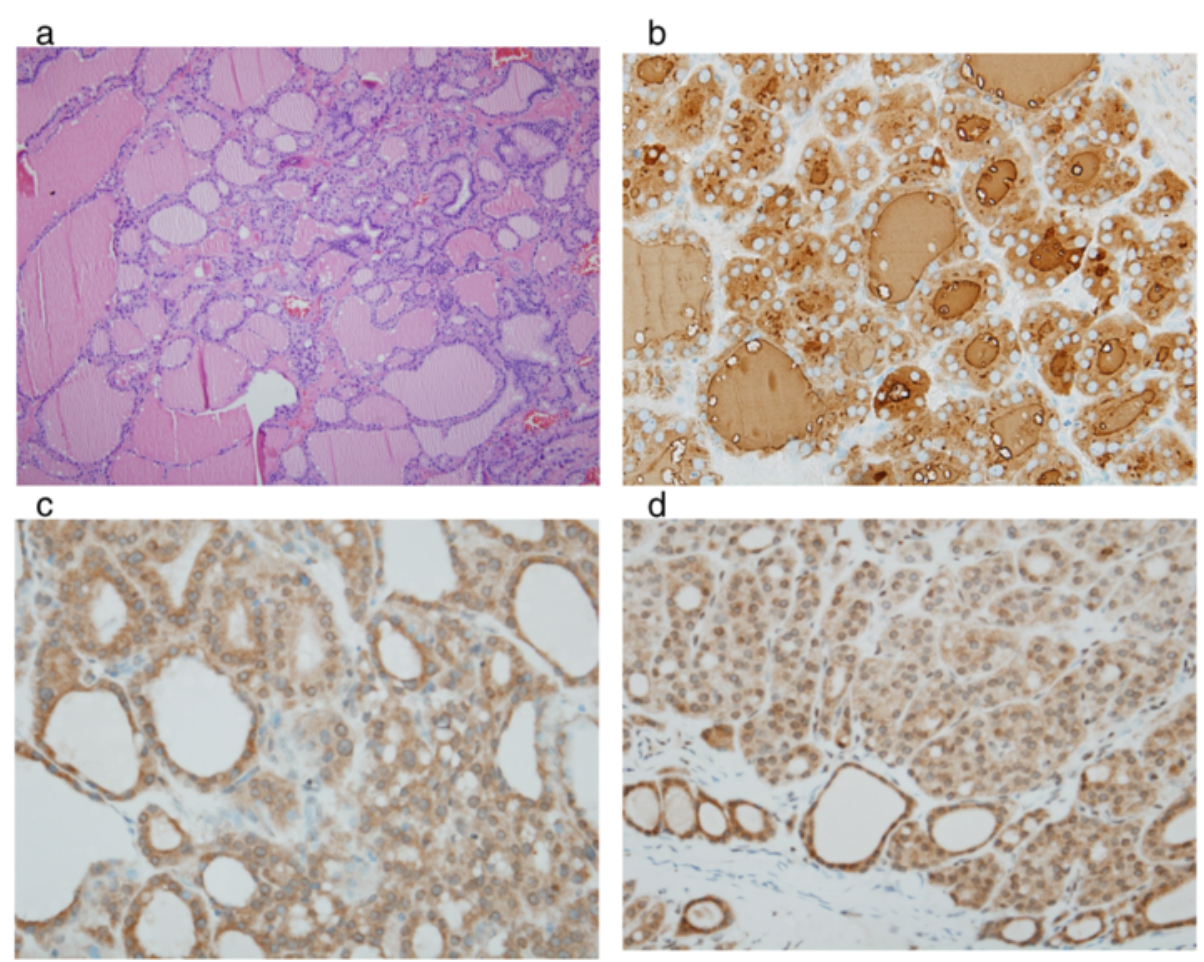

Fig. 3 a H\&E staining of our patient's ovarian section revealed typical thyroid follicles. b The thyroid tissue in our patient's ovarian tumor was highlighted by thyroglobulin antibody. c Immunostaining for TSH receptor showed positive staining in our patient's struma ovarii. d TSH receptor also expressed on the tumor cells from other patient with non-functioning struma ovarii

thyroid bed and biochemical hypothyroidism after removal of the struma ovarii confirmed the diagnosis of a functioning struma ovarii.

The pathophysiology of thyrotoxicosis from struma ovarii remains unclear. The finding of tall thyroidal epithelium with scattered papillary infoldings, which is frequently found in struma ovarii, has a poor correlation with the presence of clinical thyrotoxicosis [7]. There are two proposed mechanisms underlying the pathophysiology of functioning struma ovarii. First, the ovarian tumor may have autonomous function, as in toxic multinodular goiter [7]. Second, in patients with coexisting Graves' disease, TSHR antibodies stimulate the struma ovarii in the same way that they stimulate the thyroid tissue to cause Graves' disease. Our patient's ovarian section revealed typical thyroid follicles without features of malignancy. Immunohistochemical staining for the TSHR in the struma ovarii tissue was positive (Fig. 3c), thus supporting the second hypothesis [3, 4]. We performed TSHR staining in the struma ovarii of another patient with normal thyroid function test preoperatively and two other patients without confirm thyroid function test but was clinically euthyroid preoperatively. The staining results were all positive and the intensity of the TSHR staining of functioning strum ovarii was the same as that in other cases of nonfunctioning struma ovarii (Fig. 3d), suggesting that the determinant of functioning struma ovarii might be the presence of TSHR stimuli rather than the intensity of the TSHR in the ovarian tissue. In prior case reports of coexisting Graves' disease and struma ovarii, the diagnosis of functioning struma ovarii almost always follows the diagnosis of Graves' disease by several years. The circulating TSHR antibody in Graves' disease presumably has a stimulatory effect on the thyroid tissue in the ovary, resulting in gradual growth and increased thyroid hormone production $[3,15]$.

Approximately $5 \%$ of struma ovarii are malignant, regardless of whether they are functional, and tissue sampling for malignancy testing is very difficult. Therefore, struma ovarii should be surgically removed in all cases. Meanwhile, the coexisting Graves' disease can be managed medically, surgically, or by radioactive iodine ablation.

\section{Conclusions}

In patients with Graves' disease with persistent or recurrent thyrotoxicosis after adequate ablative treatment, the possibility of ectopic thyroid hormone production such as that from struma ovarii or a metastatic differentiated thyroid cancer should be considered. TSHR expression is found in patients with functioning and non-functioning 
Table 2 Cases of Coexisting Graves' disease and Functioning Struma Ovarii

\begin{tabular}{|c|c|c|c|c|c|c|c|c|c|c|c|c|c|c|}
\hline \multirow[t]{2}{*}{ Author, year } & \multirow{2}{*}{$\begin{array}{l}\text { Age at } \\
\text { diagnosis }\end{array}$} & \multicolumn{5}{|c|}{ Presentation } & \multirow{2}{*}{$\begin{array}{l}\text { TSH receptor } \\
\text { antibody }\end{array}$} & \multirow{2}{*}{$\begin{array}{l}\text { Cervical } \\
\text { thyroidectomy } \\
\text { before } \\
\text { diagnosis } \\
\text { struma ovarii }\end{array}$} & \multirow{2}{*}{$\begin{array}{l}\text { Prior pelvic } \\
\text { exam that result } \\
\text { negative }\end{array}$} & \multirow{2}{*}{$\begin{array}{l}\text { Ovarian scan } \\
\text { before abdominal } \\
\text { surgery }\end{array}$} & \multicolumn{3}{|c|}{ Ovarian findings } & \multirow{2}{*}{$\begin{array}{l}\text { Years after } \\
\text { Graves' disease } \\
\text { diagnosis }\end{array}$} \\
\hline & & $\begin{array}{l}\text { Exoph- } \\
\text { thalmos }\end{array}$ & $\begin{array}{l}\text { Thyroid } \\
\text { bruit }\end{array}$ & $\begin{array}{l}\text { Pelvic } \\
\text { pressure } \\
\text { symptoms }\end{array}$ & $\begin{array}{l}\text { Pleural } \\
\text { effusion }\end{array}$ & Ascites & & & & & Side & $\begin{array}{l}\text { Maximum } \\
\text { diameter }(\mathrm{cm})\end{array}$ & $\overline{\text { Malignancy }}$ & \\
\hline $\begin{array}{l}\text { Kampers, } \\
1970[7]\end{array}$ & 64 & Yes & NA & NA & NA & NA & NA & Yes & NA & NA & NA & NA & No & 18 \\
\hline $\begin{array}{l}\text { Lefort, } \\
1981[9]\end{array}$ & 38 & Yes & NA & NA & No & No & Positive & NA & NA & Positive & Right & 7 & No & 12 \\
\hline $\begin{array}{l}\text { Lazarus, } \\
1987[15]\end{array}$ & 48 & Yes & NA & NA & NA & Few & Positive & Yes & 14 years & Positive & Left & 9 & No & 24 \\
\hline $\begin{array}{l}\text { Kung, } \\
1990 \text { [10] }\end{array}$ & 40 & No & NA & No & NA & No & Positive & No & 23 weeks & NA & Right & 5 & No & 4 \\
\hline $\begin{array}{l}\text { Banyot, } \\
1995 \text { [1] }\end{array}$ & 30 & No & No & Yes & NA & NA & Negative & No & NA & Positive & Right & 7 & NA & 0 \\
\hline $\begin{array}{l}\text { Grandet, } \\
2000 \text { [16] }\end{array}$ & 78 & NA & NA & NA & NA & Few & NA & Yes & NA & Positive & Bilateral & 10 & No & 4 \\
\hline $\begin{array}{l}\text { Kano, } \\
2000[8]\end{array}$ & 50 & NA & NA & NA & NA & Yes & Positive & No & NA & NA & Left & 7 & Yes & 0 \\
\hline $\begin{array}{l}\text { Mimura, } \\
2001[6]\end{array}$ & 26 & No & No & NA & NA & NA & Positive & No & NA & Positive & Left & 16 & No & 4 \\
\hline $\begin{array}{l}\text { Sussman, } \\
2002 \text { [17] }\end{array}$ & 53 & No & NA & No & NA & NA & NA & No & NA & NA & Right & 7.5 & Yes & 5 \\
\hline $\begin{array}{l}\text { Bartel, } \\
2005 \text { [18] }\end{array}$ & 54 & NA & NA & NA & NA & NA & Positive & Yes & NA & Positive & Left & NA & No & 23 \\
\hline $\begin{array}{l}\text { Guida, } \\
2005 \text { [11] }\end{array}$ & 42 & Yes & NA & NA & No & Marked & NA & Yes & NA & Negative & Right & 12 & No & 1 \\
\hline $\begin{array}{l}\text { Teale, } \\
2006[4]\end{array}$ & 36 & Yes & NA & NA & NA & NA & Positive & Yes & NA & NA & Left & 13.5 & No & 8 \\
\hline $\begin{array}{l}\text { Chiofalo, } \\
2007 \text { [19] }\end{array}$ & 42 & No & NA & Yes & NA & Yes & Positive & Yes & NA & Positive & Right & 12 & No & 0.5 \\
\hline $\begin{array}{l}\text { Wong, } \\
2009[2]\end{array}$ & 44 & Yes & Yes & Yes & NA & NA & Positive & Yes & NA & NA & Left & NA & Yes & 1 \\
\hline $\begin{array}{l}\text { Anastasilakis, } \\
2013 \text { [3] }\end{array}$ & 49 & No & NA & NA & Yes & Moderate & Positive & No & NA & NA & Right & 18 & No & 2 \\
\hline $\begin{array}{l}\text { Our case, } \\
2015\end{array}$ & 56 & Yes & No & No & No & Minimal & Positive & Yes & Not done & Positive & Right & 8 & No & 23 \\
\hline
\end{tabular}


struma ovarii and cannot solely be used to determine the functioning status of the tumor.

\section{Consent}

Written informed consent was obtained from the patient for publication of this case report and any accompanying images. A copy of the written consent is available for review by the editor of this journal.

\section{Abbreviations}

TSHR: Thyroid-stimulating hormone receptor; ${ }^{131}$ : Radioactive iodine; TAH with BSO: Total abdominal hysterectomy with bilateral salpingo-oophorectomy; NA: Not available.

\section{Completing interests}

The authors declare that they have no competing interests.

\section{Authors' contributions}

TS treated the patient, gathered data and drafted the manuscript. SH prepared, analysed, and interpreted the histopathological samples, and critically reviewed the manuscript. TP critically reviewed the manuscript. NT treated the patient, conceptualized the case report, gathered data, and critically reviewed the manuscript. All authors approved the final version of the manuscript.

\section{Acknowledgements}

Language editing by Edanz.

\section{Author details}

'Division of Endocrinology and Metabolism, Faculty of Medicine Siriraj Hospital, Mahidol University, Bangkok 10700, Thailand. 'Department of Pathology, Faculty of Medicine Siriraj Hospital, Mahidol University, Bangkok 10700, Thailand.

Received: 31 August 2015 Accepted: 20 October 2015

Published online: 04 November 2015

\section{References}

1. Bayot MR, Chopra IJ. Coexistence of struma ovarii and Graves' disease. Thyroid. 1995;5(6):469-71.

2. Wong LY, Diamond TH. Severe ophthalmopathy developing after treatment of coexisting malignant struma ovarii and Graves' disease. Thyroid. 2009;19(10):1125-7. doi:10.1089/thy.2008.0422.

3. Anastasilakis AD, Ruggeri RM, Polyzos SA, Makras P, Molyva D, Campenni A, et al. Coexistence of Graves' disease, papillary thyroid carcinoma and unilateral benign struma ovarii: case report and review of the literature. Metabolism. 2013;62(10):1350-6. doi:10.1016/j.metabol.2013.05.013.

4. Teale E, Gouldesbrough DR, Peacey SR. Graves' disease and coexisting struma ovarii: struma expression of thyrotropin receptors and the presence of thyrotropin receptor stimulating antibodies. Thyroid. 2006;16(8):791-3. doi:10.1089/thy.2006.16.791.

5. Devaney K, Snyder R, Norris HJ, Tavassoli FA. Proliferative and histologically malignant struma ovarii: a clinicopathologic study of 54 cases. Int J Gynecol Pathol. 1993;12(4):333-43.

6. Mimura Y, Kishida M, Masuyama H, Suwaki N, Kodama J, Otsuka F, et al. Coexistence of Graves' disease and struma ovarii: case report and literature review. Endocr J. 2001;48(2):255-60.

7. Kempers RD, Dockerty MB, Hoffman DL, Bartholomew LG. Struma ovarii-ascitic, hyperthyroid, and asymptomatic syndromes. Ann Intern Med. 1970;72(6):883-93.

8. Kano H, Inoue M, Nishino T, Yoshimoto Y, Arima R. Malignant struma ovarii with Graves' disease. Gynecol Oncol. 2000;79(3):508-10. doi:10.1006/gyno.2000.5966.

9. Lefort G, Commenges-Ducos M, Denechaud M, Rivel J, Latapie JL. Ovarian goiter in Basedow's disease. Role of thyroid-stimulating immunoglobulins? Nouv Presse Med. 1981;10(26):2209-10.

10. Kung AW, Ma JT, Wang C, Young RT. Hyperthyroidism during pregnancy due to coexistence of struma ovarii and Graves' disease. Postgrad Med J. 1990;66(772):132-3.

11. Guida M, Mandato VD, Di Spiezio SA, Di Carlo C, Giordano E, Nappi C. Coexistence of Graves' disease and benign struma ovarii in a patient with marked ascites and elevated CA-125 levels. J Endocrinol Invest. 2005;28(9):827-30.

12. Ghander C, Lussato D, Conte Devolx B, Mundler O, Taieb D. Incidental diagnosis of struma ovarii after thyroidectomy for thyroid cancer: functional imaging studies and follow-up. Gynecol Oncol. 2006;102(2):378-80. doi:10.1016/j.ygyno.2006.01.047.

13. Joja I, Asakawa T, Mitsumori A, Nakagawa T, Akaki S, Yamamoto M, et al. I-123 uptake in nonfunctional struma ovarii. Clin Nucl Med. 1998;23(1):10-2.

14. Nodine JH, Maldia G. Pseudostruma ovarii. Obstet Gynecol. 1961;17:460-3.

15. Lazarus JH, Richards AR, MacPherson MJ, Dinnen JS, Williams ED, Owen GM, et al. Struma ovarii: a case report. Clin Endocrinol (Oxf). 1987;27(6):715-20.

16. Grandet PJ, Remi MH. Struma ovarii with hyperthyroidism. Clin Nucl Med. 2000;25(10):763-5.

17. Sussman SK, Kho SA, Cersosimo E, Heimann A. Coexistence of malignant struma ovarii and Graves' disease. Endocr Pract. 2002:8(5):378-80. doi:10.4158/EP.8.5.378.

18. Bartel TB, Juweid ME, O'Dorisio T, Sivitz W, Kirby P. Scintigraphic detection of benign struma ovarii in a hyperthyroid patient. J Clin Endocrinol Metab. 2005;90(6):3771-2. doi:10.1210/jc.2005-0147.

19. Chiofalo MG, Misso C, Insabato L, Lastoria S, Pezzullo L. Hyperthyroidism due to coexistence of Graves' disease and Struma ovarii. Endocr Pract. 2007;13(3):274-6. doi:10.4158/EP.13.3.274.

\section{Submit your next manuscript to BioMed Central and take full advantage of:}

- Convenient online submission

- Thorough peer review

- No space constraints or color figure charges

- Immediate publication on acceptance

- Inclusion in PubMed, CAS, Scopus and Google Scholar

- Research which is freely available for redistribution 